\title{
Pneumologia
}

\section{Post-COVID-19 infections and evolution of pulmonary and cardiac lesions - the battle has just started}

Florin Mihălțan ${ }^{1, *}$, Ancuța Constantin ${ }^{2}$

${ }^{1}$ Carol Davila University of Medicine and Pharmacy, Bucharest, Romania

${ }^{2}$ National Institute of Pneumology Marius Nasta, Bucharest, Romania

Abstract

English:

Talking only about the acute phase of COVID-19 infection is not enough. A multitude of complications has arisen after viremia, which has been generating problems for experts. Of these, lung and heart lesions remain important, and interventions, and their prevalence pose real problems for practitioners. The authors analyze these post-COVID-19 complications as well as appropriate recommendations for diagnostic and therapeutic interventions

Keywords

post COVID-19 complications $\bullet$ pulmonary lesions $\bullet$ cardiac lesions

\section{Infecții post-COVID-19 și evoluția leziunilor pulmonare și cardiace - bătălia abia începe}

Rezumat

\begin{abstract}
Romanian:
A vorbi doar despre faza acută a infecției COVID 19 nu este suficient. Au apărut o multitudine de complicații după viremie generând probleme experților. Dintre acestea cele pulmonare și cardiace rămân importante, iar intervențiile, ca și prevalența acestora, pun probleme reale practicienilor. Autorii analizează aceste complicații post COVID dar și recomandările adecvate de interventii diagnostice și terapeutice.
\end{abstract}

Cuvinte-cheie

complicații post COVID • leziuni pulmonare • leziuni cardiace

\section{Introduction}

Everyone including the authorities and specialists was surprised by the evolution of pandemic COVID-19 infection. The medical system has a lot of flaws and the authorities are being ridden by problems induced by this coronavirus. Many specialities are facing new challenges in many aspects that are discovered in the front of coronavirus infection but more and more challenging problems are now present in post-COVID-19 infections. The number of people affected by COVID-19 is unprecedented. According to the World Health Organization, $80 \%$ of SARS-CoV-2 infections are mild, $14 \%$ develop severe symptoms, and $6 \%$ will become critically ill
(1). We are facing a variety of COVID-19 sequelae starting from mild forms with unique symptoms such as fatigue and body aches to lung fibrosis.

\section{Lesson learned from other viral infections}

If we are looking at previous lessons, it is possible that ongoing active alveolitis during the host immune system response to the SARS-CoV antigen might lead to pulmonary fibrosis in some patients after recovery (Hui et al., 2005)

*Corresponding author: Florin Mihălțan

E-mail:mihaltan@starnets.ro

ว Open Access. (c) 2021 Mihălțan and Constantin, published by Sciendo

(c) BY-NC-ND This work is licensed under the Creative Commons Attribution-NonCommercial-NoDerivs 4.0 License. 
(2). A total of $30 \%$ of people with SARS or Middle East respiratory syndrome had persisting lung abnormalities after their acute illness (3). The study of Zhang et al.(4) consisting of a comprehensive 15-year follow-up on health care workers who survived nosocomial SARS infections in 2003 indicates that, even in patients with early complete resolution of chest CT abnormalities, pulmonary function took several years to return to normal. All the researchers are looking after similarities concerning episodes linked to acute-phase coming from other different viral infections such as H7N9 or SARS. Chen et al. (5) performed a 24-month follow-up study on patients with epidemic influenza A ( $\mathrm{H} 7 \mathrm{~N} 9$ ) virus infection and they found some lesions on the 3-month post-recovery chest CTs, such as linear fibrosis, focal pleural thickening, and small bullous cyst formation. Some pulmonary changes during the 6-month convalescence period can be irreversible.

\section{Pathogenic pathways for post-covid pulmonary lesions}

Post-covid fibrosis/acute respiratory distressed syndrome is a common condition in Covid-19 affected patients, which is sometimes irreversible; one explanation is that the coronavirus causes chronic inflammation in epithelial injury and fibroblast activation (6). The recovery rate to date has reached $78 \%$, and fatality rates are low (7); even so there are still people prone to various other long-term symptoms after recovery, which remains another concern for specialists.

The coronavirus causes the body to produce a long-lasting immune response that actually attacks the body instead of the virus, possibly explaining why some patients continue to have a variety of symptoms long after they are clear of infection. Post-COVID-19 syndromes could plausibly be caused by long-lived autoantibodies that persist well after the virus is cleared from the body, hypothesis sustained by some researchers from Yale (8). In a study not yet peerreviewed, Akiko Iwasaki, a professor of immunobiology at Yale, along with other researchers from the same university, found that coronavirus patients had high levels of autoantibodies that targeted organs and tissue instead of latching onto virus. Impaired diffusing capacity may also partly be of vascular origin; SARS-CoV-1 and SARSCoV-2 share several deleterious mechanisms involved in pulmonary vascular dysfunction (promoting endothelial dysfunction, lung coagulopathy and microthrombi, and hemodynamics impairments) and becoming risk factors for persistent pulmonary vascular defects and subsequent $\mathrm{PH}$ development, especially in patients with persistent lung impairment post- COVID-19, and susceptible patients with genetic predisposition or chronic lung and heart diseases (9).

\section{Pulmonary and cardiac lesions in the post-acute} phase

The lung physician remains in the first line in the convalescent phase. The lung is the most exposed organ not only at the moment of infection but also after. Post-acute COVID-19 ('long covid') seems to be a multisystem disease, sometimes occurring after a relatively mild acute illness (10). Up to $98.1 \%$ of all chest CTs will show abnormalities at $>28$ days since symptom onset (11). Some authors proposed the term postacute COVID-19 (3 weeks after the onset of first symptoms) (10\% of patients) (12) and the chronic COVID-19 (extension over 12 weeks). It's a whole list of potential pulmonary lesions postinfections and also more accumulated evidence concerning early convalescent. Organizing pneumonia and diffuse alveolar damage seem to be, by far, the most common forms of lung injury associated with COVID-19, and both evolve in a fairly predictable manner (13). Organizing pneumonia can progress to pure consolidation or may present the melted sugar sign (gradual resolution of consolidation and turning into ground-glass opacities). Another possibility is to develop consolidation to band-like opacities (parenchymal bands) in the later stages of the disease and to complicate the recovery phase (14). Evolution is binded to the patient's age, comorbidities, history of cigarette smoking, length of hospital admission, and the severity of the acute disease (such as the need for ICU admission) and the type of medications administered (such as antiviral or corticosteroid therapy) (15). Post-SARS fibrosis typically is not progressive, but nonetheless can be severe and limiting with recovery if we are looking to the SARS model in 1 year (15). This is important because we need to differentiate this type of new lesions postCOVID-19 from the consequences of acute exacerbations of idiopathic pulmonary fibrosis in COVID-19 infections leading to more than $50 \%$ mortality with a mean survival time of only a few months (16). The frequently CT occurring abnormalities are ground-glass opacities, which were found in $69.9 \%$ of the patients, irregular lesions (54.4\%), thickening of the broncho vascular bundles (39.5\%), grid form shadow and hydrothorax (24.4\% and $8.5 \%$ respectively of the individuals) (17).

Impaired diffusing capacity, lower respiratory muscle strength, and lung imaging abnormalities were detected in more than half of the COVID-19 patients in the early convalescence phase (18). These abnormalities are also a marker of the post COVID-19 echo because if the practitioner is comparing severe patients with non-severe cases, they observed a higher incidence of DLCO impairment $(75.6 \%$ vs $42.5 \%$, $P=0.019$ ) (lung diffusing capacity for carbon monoxide), more TLC (lung volumes) decrease and 6MWD (respiratory muscle strength, 6-min walking distance) decline (18). Even after 30 days after discharge $54.5 \%$ had still CT residual abnormalities ( $94.1 \%$ were severe cases vs $37.5 \%$ non-severe). There are 
similarities with SARS previous post epidemic data where the most common abnormality to the survivors was the impaired DLCO $(15.5-43.6 \%)(19,20)$ with the persistence of abnormal values after 3 years. There was a low prevalence of obstructive or restrictive functional impairment in SARS patients (21). 30 days after discharge, in some samples the researchers found decreased diffusion capacity for carbon monoxide and diminished respiratory muscle strength in $53 \%$ patients and $49 \%$, respectively even more after (18), even more 3 months after discharge, $25 \%$ of patients still kept decreased diffusion capacity for carbon monoxide (22). In a pooled analysis of studies, other authors found that complications commonly observed were impaired diffusing capacity for carbon monoxide (DLCO) [the prevalence of $27.26 \%, 95 \% \mathrm{Cl} 14.87-44.57]$ and reduced exercise capacity [(6-minute walking distance (6MWD) mean $461 \mathrm{~m}, 95 \% \mathrm{Cl}$ 449.66-472.71] at 6 months with limited improvement beyond 6 months (23).

Post-COVID-19 fibrosis or post-ARDS fibrosis is one of the potential complications. Whether there is any overlap between the residual pulmonary consequences of COVID-19 pneumonia and non-specific interstitial pneumonia (NSIP) or usual interstitial pneumonia (UIP) is not known yet. It might be the viral infection itself, but it might also be the cytokine storm that can follow infection, and it might even be related to ventilation. Duration of disease is an important determinant for lung fibrosis post-ARDS ( $4 \%$ of patients with a disease duration of less than 1 week, $24 \%$ of patients with a disease duration of between weeks 1 and 3 , and $61 \%$ of patients with a disease duration of greater than 3 weeks, developed fibrosis) (24). Some authors defined also other risk factors for post-COVID fibrosis, such as advanced age, increased severity of diseases (comorbidities such as hypertension, diabetes, and coronary artery diseases), prolonged ICU stay and duration of mechanical ventilation, smoking status, alcohol abuse and the type of medications administered (such as antiviral or corticosteroid therapy) (25). The possible mechanisms are: a cytokine release syndrome triggered by the viral antigen, drug-induced pulmonary toxicity, high airway pressure and hyperoxia-induced acute lung injury secondary to mechanical ventilation (26). Other scientists found other factors that determine persistent respiratory impairment in survivors, in particular the use of antiviral agents, systemic corticosteroids, other immunomodulating or anti-inflammatory agents, advanced life support with invasive or non-invasive ventilation or extracorporeal membrane oxygenation (27). The level of D-dimer was an important prognostic factor for abnormal DLCO and severity of the disease. Patients who have marked raised D-dimer, need pulmonary rehabilitation even in the absence of severity respiratory (22).

\section{Long-term symptoms and expression in post-COVID-19}

Symptoms persisting after COVID 19 infections are also important for the quality of life of all these people. In patients who recovered $87.4 \%$ reported at least one symptom (very frequently fatigability and dyspnea) but also joint and chest pain and less other like cough, headache, lack of appetite and myalgia. At 2 months only $12.6 \%$ were symptoms-free, $32 \%$ had one or two symptoms, and $55 \%$ had three or more. Quality of life worsened in $44.1 \%$ of the patients' samples (28). Not returning to usual health within $2-3$ weeks of testing was reported by other authors approximately to onethird of respondents (29). Looking at other viral infection consequences such as SARS (severe acute respiratory syndromes) we can expect not only respiratory symptoms after a long period of surveillance but also mental disturbances. After SARS, a study made after 41.3 months founds that over $40 \%$ of the respondents with active psychiatric illnesses, $40.3 \%$ with chronic fatigue problem, and $27.1 \%$ met the modified 1994 Centers for Disease Control and Prevention criteria for chronic fatigue syndrome (30). The list of symptoms is and remains very large in this whole pandemic period. Symptoms such as cough, shortness of breath, and nasal congestion prevail after the recovery in approx. $30 \%$ of the patients for longer durations $(31,32)$. There are common relapsing or remitting symptoms such as cough, low-grade fever, and fatigue $(33,34)$. Other possibilities are shortness of breath, chest pain, headaches, neurocognitive difficulties, muscle pains and weakness, gastrointestinal upset, rashes, metabolic disruption (such as poor control of diabetes), thromboembolic conditions, and depression and other mental health conditions. If we are looking only at symptoms there are some specific therapeutical recommendations adapted to the type of symptoms (35):

- for cough, simple breathing control exercises and medication where indicated (such as proton pump inhibitors if reflux is suspected) (36)

- for breathlessness, pulse oximetry surveillance and breathing exercises are useful (36). British Thoracic Society guidelines are also defining the target range for oxygen saturation as 94 $98 \%$ and a level of $92 \%$ or below as requiring supplementary oxygen (unless the patient is in chronic respiratory failure) (37). Rehabilitation can be delivered by various virtual models, including video linked classes and home education booklets with additional telephone support (35)

- for fatigue, the Cochrane recommendations (34) are graded exercises (with precocious and cut back if the patient develops fever, breathlessness, severe fatigue, or muscle aches (38). 
Chest pain (very evident in older people) another possible symptom after COVID 19 must be analyzed carefully. The clinical priority is to separate musculoskeletal and other non-specific chest pain but also to exclude cardiovascular sufferance like thromboembolism, ventricular dysfunction after myocarditis, pericarditis.

For other neurological sequelae with symptoms such as breathlessness, headaches, dizziness, and cognitive blunting ('brain fog') until now the only recommendations are supportive management and symptom monitoring in primary care (33).

Older people need more personalized assistance from the multi-professional team (for example, general practitioner, district nurse, social worker, rehabilitation teams, and occupational therapists) because they have a high risk of sarcopenia, malnutrition, depression, and delirium (39).

\section{Cardiac long-term lesions in connection to pulmonary sufferance}

Cardiac involvement in these viral infections is also important. A total of $35 \%$ of the patients who died of COVID-19 were detected with the presence of the virus in the myocardium (40). The survivors also suffered from cardiac diseases including arrhythmias, myocardial infarction, sudden cardiac death and systolic and diastolic functions (41). In a German cohort, authors revealed cardiac involvement with cardiovascular magnetic resonance in $78 \%$ of patients (after a median time of 71 days from the diagnosis moment) and ongoing myocardial inflammation in $60 \%$, independent of preexisting conditions, severity and overall course of the acute illness, and time from the original diagnosis (42). Months after a COVID-19 diagnosis, other possible cardiac complications that arise are residual left ventricular dysfunction and ongoing inflammation, both representing a nidus for new-onset heart failure, cardiomyopathy and other future cardiovascular complications (43). Patients with known cardiovascular diseases (CVD) but without elevated troponins had a more favourable outcome (44). In a long-term follow-up study in patients who recovered from acute myocarditis (mean age 40.2 years), 6-8\% developed heart failure, cardiomyopathy and cardiac arrhythmias hospitalizations (45). Screening for residual cardiac involvement in the convalescent phase is needed and long term studies also to establish the population burden of long-term cardiac disease contributed to by COVID-19 (standard ECG and echocardiogram and possibly a cardiac monitor 2-6 months post-recovery, MRI with gadolinium enhancement, or echocardiographic strain when initial testing or clinical examinations reveals abnormalities) (46). Heightened systemic inflammatory and pro-coagulant activity can persist long after resolution of the index infection. We need future prospective studies to understand the long-term impact of COVID-19, its connections with lung lesions and to establish a future strategy for protecting these patients from CVD.

\section{Recommendations of investigations and therapy post-COVID-19}

The French Society of Pneumology (SPLF) proposed an algorithm of surveillance of patients with pulmonary complications post-COVID-19 (47). For all practitioners, it's very important to judge correctly every step after the COVID-19 infection. If the patient has persistent dyspnea (47) 12 weeks after the Day 0 of infection, with no obvious aetiology at the end of the functional check-up proposed initially, it is important to check for anaemia, thromboembolic disease, heart disease, deconditioning, syndrome hyperventilation and diaphragmatic pathology. The French society experts are proposing (47) also a thoracic CT scan, thoracic and respiratory functional testing, adding after exclusion of cardiac diseases a test of effort with the completion of VO2max. All the guidelines need to introduce early rehabilitation. For patients having CT-scan abnormalities (extended or multifocal frosted glass type, 'new' anomalies, such as nodules, condensations, reticular design, and bronchiectasis) the proposals are a bronchial endoscopy with broncho-alveolar lavage (LBA) with a cytological purpose and microbiological analysis and blood tests including the search for auto-immunity (antinuclear antibodies, nucleus soluble anti-antigen antibodies, rheumatoid factor, citrullinated cyclic anti-peptide and anticytoplasm antibodies of neutrophils, etc.) (47). All these tests should be conducted before the introduction of corticosteroid therapy or antifibrotic therapy. It is also proposed by the French experts to assess the respiratory functional impact with plethysmography, DLCO, arterial blood gas and a 6-minute walking test. For cases where it is a progress of radiological lesions, it is necessary to have a multidisciplinary approach and oxygen therapy. For persisting symptoms such as cough, it is important to eliminate the classic chronic cough causes (ENT causes, gastroesophageal reflux disease, iatrogenic cause, etc.) and to look for bronchial hyperreactivity by a methacholine test and the proposal of treatment if the patient had an obstructive respiratory disease is inhaling corticoids plus/minus bronchodilator (47). At the same time for a patient with SARS-CoV-2 infection and with 'persistent' CT abnormalities (extended or multifocal frosted glass type), or 'new (such as nodules, condensations, reticulations, with or without traction bronchiectasis), and dyspnea and/or cough and/or abnormalities less than a year from the start of a SARS-CoV-2 infection, it is proposed to prescribe, after multidisciplinary discussion, oral corticosteroid therapy (if there are no contraindications and no active infection) (47). 
For organized fibrosis or pneumonia, corticosteroid therapy in delayed forms of COVID-19, after the acute phase, is one option in the event of persistence of the parenchymatous opacities (starting with $0.5 \mathrm{mg} / \mathrm{kg} /$ day 1 month and diminishing every month with $10 \mathrm{mg} /$ day) (47). A new CT scan and DLCO control are recommended after 3 months. The effectiveness of anti-fibrotic drugs in the context of persistent abnormalities post-COVID-19 is not known at this moment. Studies are running abundant in this period. The benefit of corticoids such as dexamethasone in severe COVID-19 has recently been established, but there are two additional problems if we are looking to post-COVID-19 period:

1. This treatment did not improve acute outcomes among patients with the milder disease (48).

2. The longer-term implications of steroids in the management of COVID-19 have not yet been evaluated but widespread use cannot be recommended due to the substantial morbidity associated with these agents.

The possibility of shared mechanisms of fibrosis between ARDS cases and chronic ILDs raises the potential that therapies (pirfenidone and nintedanib) that treat ILDs could also be beneficial to COVID-19 associated lung disease (49, 26). Guidelines published by the British Thoracic Society are more simple (50). They recommend chest radiography 3 months after discharge for all patients admitted to the hospital with COVID-19. For those with a history of moderate or severe disease, with persisting symptoms or with radiological abnormalities, the specialists require clinical review and further investigation. An integrated multidisciplinary approach involving doctors, physiotherapists, and psychotherapists is likely to be needed in every moment after post-COVID-19 recovery.

\section{Conclusions}

Reliable treatment for the disease is yet to be discovered. What we need to know for the next months or years is how to manage and what therapy we need to choose for preventing all these types of complications. Outpatient postCOVID-19 clinics are opening in many countries where large outbreaks have occurred, and the term 'long-haulers' has been suggested to refer to these patients (51). Multisite and multinational projects organized by international and interdisciplinary groups of researchers are needed because a description from one group or one site cannot discern between universal features and features of the local health system or the local population. At the same time, we need more research on connections between symptoms, patient clinical data and the sequelae. It's necessary to see exactly which symptoms might be explained by the anxiety caused by a new disease and by the isolation, and which symptoms are secondary to a complicated form of COVID-19 (e.g. pulmonary involvement during the acute disease). Concerning the pathogeny, we have to find out if the mechanisms underlying the long-term consequences are immunological or caused by new or relapsing inflammation, ongoing infection, or side effects of immunomodulatory treatment (52). All these longterm pulmonary consequences of COVID-19 which remain until now are speculative and should not be assumed without appropriate prospective study (26).

\section{References}

1. Ojo AS, Balogun SA, Williams OT, Ojo OS. Pulmonary fibrosis in COVID-19 survivors: Predictive factors and risk reduction strategies. Pulmonary Medicine. 2020;10. Available from: doi: 10.1155/2020/6175964.

2. Hui DS, Joynt GM, Wong KT, Gomersall CD, Li TS, Antonio G. Impactofsevereacute respiratorysyndrome(SARS)on pulmonary function, functional capacity and quality of life in a cohort of survivors. Thorax. 2005;60(5): 401-409.

3. NHS England. Aftercare needs of inpatients recovering from COVID-19. Jun 2020. Available from: https://www.england.nhs. uk/coronavirus/publication/after-care-needs-of-inpatients-recovering from-covid-19.

4. Zhang P, Li J, Liu H, Han N, Ju J, Kou Y, et al. Long-term bone and lung consequences associated with hospital-acquired severe acute respiratory syndrome: a 15-year follow-up from a prospective cohort study. Bone Research. 2020;8: 8.

5. Chen J, Wu J, Hao S, Yang M, Lu X, Chen X, et al. Long term outcomes in survivors of epidemic influenza A (H7N9) virus infection. Scientific Reports. 2017;7: 17275.

6. Zuo W, Zhao X, Chen YG. SARS Coronavirus and lung fibrosis. Molecular biology of the SARS-Coronavirus. 2009;247-258. Published 2009 Jul 22. Available from: doi: 10.1007/978-3-64203683-5_15.

7. Ioshi A. Long term complications associated with Covid-19: a review. International Journal of Innovative Science and Research Technology 2020;5(9): 324-326.

8. TOI STAFF-(Akiko Iwasaki, a professor of immunobiology at Yale interview)- 'Long COVID' may be caused by body attacking itself, not the virus - study-14 December 2020, The Times from Israel.

9. Potus F, Mai V, Lebret M, Malenfant S, Breton-Gagnon E, Lajoie AC. Novel insights on the pulmonary vascular consequences of COVID-19. American Journal of Physiology-Lung Cellular and Molecular Physiology. 2020;319(2): L277-L288.

10. Geddes L. Why strange and debilitating coronavirus symptoms can last for months. Scientist 2020. Available from: https://www. newscientist.com/article/mg24632881-400-why-strange-anddebilitating corona virus - symptoms-can-last-for-months/. 
11. Ding X, Xu J, Zhou J, Long Q. Chest CT findings of COVID-19 pneumonia by duration of symptoms. European Journal of Radiology. 2020;127: 109009. Available from: doi: 10.1016/j. ejrad.2020.10900 9

12. COVID Symptom Study. How long does COVID-19 last? Kings College London; 2020. Available from https://covid19.joinzoe. com/post/covid-long-term?fbclid=IwAR1RxIcmmdL-EFjh_al-.

13. Tian S, Xiong Y, Liu H, Niu L, Guo J, Liao M, et al. Pathological study of the 2019 novel coronavirus disease (COVID-19) through postmortem core biopsies. Modern Pathology. 2020. Available from: doi: 10.1038/s41379-020-0536-x.

14. Marchiori E, Hochhegger B, Zanetti G. Organising pneumonia as a late abnormality in influenza $A(\mathrm{H} 1 \mathrm{~N} 1)$ virus infection. The British Journal of Radiology. 2012;85: 841; author reply 842.

15. Ong K-C, Ng AW-K, Lee LS-U, Kaw G, Kwek S-K, Leow MK-S, et al. 1-year pulmonary function and health status in survivors of severe acute respiratory syndrome. Chest. 2005;128: 1393-1400.

16. Kreuter M, Polke M, Walsh SL, Krisam J, Collard HR, Chaudhuri $\mathrm{N}$, et al. Acute exacerbation of idiopathic pulmonary fibrosis: international survey and call for harmonization. European Respiratory Journal. 2020;55(4): 1901760.

17. Cao Y, Liu X, Xiong L, Cai K. Imaging and clinical features of patients with 2019 novel coronavirus SARS-CoV-2: a systematic review and meta-analysis. Journal of Medical Virology. 2020. Available from: doi: 10.1002/jmv.25822.

18. Huang Y, Tan C, Wu J, Chen M, Wang Z, Luo L, et al. Impact of coronavirus disease 2019 on pulmonary function in early convalescence phase. Respiratory Research. 2020;21: 163. Available from: doi: 10.1186/s12931-020-01429-6.

19. Hui DS, Wong KT, Ko FW, Tam LS, Chan DP, Woo J, et al. The 1-year impact of severe acute respiratory syndrome on pulmonary function, exercise capacity, and quality of life in a cohort of survivors. Chest. 2005;128(4): 2247-2261.

20. Zheng Z, Chen R, Wu H, Liu X, He W, Xu Y, et al. Changes in pulmonary function in severe acute respiratory syndrome patients during convalescent period. Zhongguo Wei Zhong Bing Ji Jiu Yi Xue. 2005;17(6): 329.

21. NGAI JC, Ko FW, Ng SS, To K-W, Tong M, Hui DS. The longterm impact of severe acute respiratory syndrome on pulmonary function, exercise capacity and health status. Respirology. 2010;15(3): 543-550.

22. Zhao YM, Shang YM, Song WB, Li Q-Q, Xie H, Xu QF, et al. Follow-up study of the pulmonary function and related physiological characteristics of COVID-19 survivors three months after recovery. E ClinicalMedicine. 2020;25: 100463. Available from: doi: 10.1016/j.eclinm.2020.100463.

23. Ahmed H, Patel K, Greenwood D, Halpin St., Lewthwaite P, Salawu A, et al. Long-term clinical outcomes in survivors of coronavirus outbreaks after hospitalisation or ICU admission: a systematic review and meta-analysis of follow-up studies. medRxiv. 2020.04.16.20067975; Available from: doi: $10.1101 / 2020.04 .16 .20067975$.
24. Cardinal-Fernández P, Lorente JA, Ballén-Barragán A, MatuteBello $G$. Acute respiratory distress syndrome and diffuse alveolar damage. New insights on a complex relationship. Annals of the American Thoracic Society. 2017;14: 844-850.

25. Kumar Rai D, Sharma P, Kumar R. Post covid 19 pulmonary fibrosis- Is it reversible? Indian Journal of Tuberculosis, 2020, Available from: doi: 10.1016/j.ijtb.2020.11.003. Available from: http://www.sciencedirect.com/science/article/pii/ S0019570720302134.

26. Spagnolo P, Balestro E, Aliberti S, Cocconcelli E, Biondini D, Casa GD, et al. Pulmonary fibrosis secondary to COVID-19: a call to arms? Lancet Respiratory Medicine. 2020;8(8): 750-752.

27. Leung TYM, Chan AYL, Chan EW, Chan VKY, Chui CSL, Cowling BJ, et al. Short- and potential long-term adverse health outcomes of COVID-19: a rapid review. Emerging Microbes \& Infections. 2020;9(1): 2190-2199.

28. Carfi A, Bernabei R, Landi F, for the Gemelli Against COVID-19 Post-Acute Care Study Group. Persistent symptoms in patients after acute COVID-19. JAMA. 2020;324(6): 603-605.

29. Tenforde MW, Kim SS, Lindsell CJ, Rose EB., Shapiro NI, Files $\mathrm{DC}$, et al. Symptom duration and risk factors for delayed return to usual health among outpatients with COVID-19 in a multistate health care systems network - United States, March-June 2020. Morbidity and Mortality Weekly Report. 2020;69: 993-998.

30. Lam MH-B, Wing Y-K, Yu MW-M, Leung C-M, Ma RCW, Kong APS, et al. Mental morbidities and chronic fatigue in severe acute respiratory syndrome survivors: long-term Follow-up. Archives of Internal Medicine. 2009;169(22): 2142-2147.

31. Dhama K, Khan S, Tiwari R, Sircar S, Bhat S, Malik YS, et al. Rodriguez-Morales Coronavirus Disease 2019-COVID-19. Available from: doi: 10.1128/CMR.00028-20.

32. Fraser E. Long term respiratory complications of covid-19. BMJ. 2020;370: m3001. Available from: doi: 10.1136/bmj.m3001 (Published 03 August 2020.

33. Assaf G, Davis H, McCorkell L, Wei H, Brooke O, Akrami A, et al. An analysis of the prolonged COVID-19 symptoms survey by Patient-Led Research Team. Patient Led Research, 2020. Available from: https://patientresearchcovid19.com/.

34. Larun L, Brurberg KG, Odgaard-Jensen J, Price JR. Exercise therapy for chronic fatigue syndrome. Cochrane Database of Systematic Reviews. 2017;4: PMID: 28444695.

35. Trisha G, Matthew K, Christine A'C, Maria B, Laiba H. Management of post-acute covid-19 in primary care. BMJ. 2020;370: m3026.

36. Homerton University Hospital. Post COVID-19 patient information pack. 2020. Available from: https://www.hackneycitizen.co.uk/wpcontent/uploads/Post-COVID-19-information-pack5.pdf.

37. O'Driscoll BR, Howard LS, Earis J, Mak V; British Thoracic Society Emergency Oxygen Guideline Group; BTS Emergency Oxygen Guideline Development Group. BTS guideline for oxygen use in adults in healthcare and emergency settings. Thorax. 2017;72(Suppl 1): ii1-90. 
38. National Institute for Health and Care Excellence. Statement about graded exercise therapy in the context of COVID-19. In: Myalgic encephalomyelitis (or encephalopathy)/chronic fatigue syndrome: diagnosis and management (in development GID-NG10091). 2020. Available from: http://www.nice.org.uk/ guidance/gid-ng10091/documents/statement.

39. Hoffman GJ, Webster NJ, Bynum JPW. A framework for agingfriendly services and supports in the age of COVID-19. Journal of Aging \& Social Policy. 2020;32: 450-459.

40. Mitrani RD, Dabas N, Goldberger JJ. COVID-19 cardiac injury: implications for long-term surveillance and outcomes in survivors. 2020;17(11): 1984-1990. Available from: doi: 10.1016/J. HRTHM.2020.06.0 26.

41. Oudit GY, Kassiri Z, Jiang C, Liu PP, Poutanen SM, Penninger JM, et al. SARS-coronavirus modulation of myocardial ACE2 expression and inflammation in patients with SARS. European Journal of Clinical Investigation. 2009;39(7): 618-625. Available from: doi: 10.1111/j.1365-2362.2009.02153.x.

42. Puntmann VO, Carerj ML, Wieters I, Fahim M, Arendt C, Hoffmann $\mathrm{J}$, et al. Outcomes of cardiovascular magnetic resonance imaging (MRI) in patients recently recovered from coronavirus disease 2019 (COVID-19). JAMA Cardiology. 2020;5(11): 1265-1273.

43. Yancy CW, Fonarow GC. Coronavirus disease 2019 (COVID-19) and the heart - is heart failure the next chapter? JAMA Cardiology. 2020;5(11): 1216-1217.

44. Guo T, Fan Y, Chen M, Wu X, Zhang L, He T, et al. Cardiovascular implications of fatal outcomes of patients with coronavirus disease 2019 (COVID-19). JAMA Cardiology. 2020;5(7): 811-818.

45. Chang J-J, Lin M-S, Chen T-H, Chen D-Y, Chen S-W, Hsu J-T, et al. Heart failure and mortality of adult survivors from acute myocarditis requiring intensive care treatment - a Nationwide Cohort Study. International Journal of Medical Sciences. 2017;14: 1241-1250.

46. Mitrani RD, Abas N, Goldberger JJ. COVID-19 cardiac injury: Implications for long-term surveillance and outcomes in survivors. Heart Rhythm. 2020;17: 1984-1990.

47. Andrejak C, Cottin V, Crestani B, Debieuvre D, Bermejo J-G, Panzini $\mathrm{CM}$, et al. Guide de prise en charge des séquelles respiratoires post infection à SARS-CoV-2. Propositions de prise en charge élaborées par la Société de Pneumologie de Langue Francaise. Version du 10 novembre 2020. Revue des Maladies Respiratoires. 2020, Available from: doi: 10.1016/j. rmr.2020.11.009.

48. Horby P, Lim WS, Emberson J, Mafham M, Bell J, Linsell L, et al. Effect of dexamethasone in hospitalized patients with covid-19: preliminary report. MedRxiv 20202020.2006.2022.20137273 [Preprint]. Available from: https://www.medrxiv.org/content/10.1 101/2020.06.22.20137273v1.

49. George PM, Wells AU, Jenkins RG. Pulmonary fibrosis and COVID-19: the potential role for antifibrotic therapy. The Lancet Respiratory Medicine. 2020;8(8): P507-P515. Available from: doi: 10.1016/S2213-2600(20)30225-3.

50. British Thoracic Society. Guidance on respiratory follow up of patients with a clinico-radiological diagnosis of covid-19 pneumonia. 2020. Available from: www.brit-thoracic.org.uk.

51. del Rio C, Collins LF, Malani P. Long-term Health Consequences of COVID-19. JAMA. 2020;324(17): 1723-1724.

52. Yelin D, Wirtheim E, Vetter P, Kalil AC, Bruchfeld J, Runold M, et al. Long-term consequences of COVID-19: research needs. Lancet Infectious Diseases. 2020;20(10): 1115-1117. 